\title{
The Effects of Consumers' Buying Behavior on E-Commerce Pricing in the Highly Developed Emerging Market: The Case of Singapore
}

\author{
Jia Yun Moerth-Teo ${ }^{1}$, Vito Bobek ${ }^{1}$, Tatjana Horvat ${ }^{2} \&$ Franko Milost $^{2}$ \\ ${ }^{1}$ University of Applied Sciences FH Joanneum, Graz, Austria \\ ${ }^{2}$ University of Primorska, Faculty of Management, Koper, Slovenia \\ Correspondence: Tatjana Horvat, University of Primorska Faculty of Management, Koper, Izolska vrata 2, 6000 \\ Koper, Slovenia. Tel: 386-4174-5448.
}

Received: August 30, 2021

Accepted: October 26, 2021

Online Published: November 5, 2021

doi:10.5539/ijef.v13n12p55

URL: https://doi.org/10.5539/ijef.v13n12p55

\begin{abstract}
This paper is focused on Singapore and its e-commerce markets. It contains the theoretical part and the conduct of an empirical study where the results are studied. This study is further extended as an investigation of the effects of consumers' buying behavior on the e-commerce market in the case of Singapore, a highly developed emerging market. This research aims to gain a detailed insight and better understand Singaporeans buying behavior and how it may or may not affect the e-commerce market.
\end{abstract}

Keywords: E-commerce, pricing, buying behaviours, consumers, Singapore

JEL codes: L81, D91.

\section{Introduction}

Fundamentally, e-commerce is a form of business with transactions of buying and selling goods or services over the worldwide net. From mobile shopping to online payment encryption and beyond, surrounding e-commerce is a wide variety of data, systems, and tools for online users, buyers, and sellers alike. Most businesses with an e-commerce presence use an e-commerce store and/or an e-commerce platform to conduct their online marketing and sales activities and oversee their logistics and fulfillment (Moore, n. d.). Since then, the growth of many e-commerce companies has ascended across the board.

The introduction and role of e-commerce platforms have created an enormous impact and have taken the entire world by storm. In recent years, there has been a trend observed in the rise of retail e-commerce globally. The worldwide e-commerce trend has been seen as an ever-increasing climb upwards and is forecasted to grow continuously upwards from 2021 to 2023. E-commerce is proliferating, that it is already slowly eating away parts of the shares from traditional retail (Wonderflow, 2019). Based on the OECD, they believe that the growth of e-commerce can increase the competition within retail markets, enhance consumer choices significantly, and prompt and facilitate innovation in the product distribution section.

\subsection{Problem Statement}

This research will be focused on the Singaporean e-commerce market and its users' buying behaviors, so it would be worthwhile to look into some of the statistics of its e-commerce scene. The revenue of the e-commerce market in Singapore has increased and is projected to reach up to 3.8 million in 2024. The number of users exposed to e-commerce in Singapore is forecasted to increase to 3.9 million by 2024, which amounts to $67 \%$ of its total current population of 5,8 million (Statista, n. d.). Due to its enduring popularity as well as the increasing importance and relevance of e-commerce both globally and especially in Singapore, it might be compelling to delve deeper in and take a closer look into this topic and to conduct the research with a focus on the consumers' buying behaviors in a highly developed emerging market, Singapore and how it might affect the e-commerce market. As time passes, mutations and evolution are expected from the consumers' buying behaviors.

As online consumers ourselves, there are many factors that we will put into consideration before deciding to purchase something through an online platform. Therein lies a considerable number of factors that may affect every consumer's buying behaviors. Based on Kotler and Armstrong, four categorical groups classify the factors affecting consumers' behaviors: psychological, personal, social, and cultural (The Open University, n. d). 
The research was conducted from many studies. The majority of them revolved around the impact and/or effects of e-commerce on consumers' buying behavior. This research and its area of work will contribute to the big picture with studies of the consumers' buying behaviors and how they might impact the e-commerce market, focusing on the Singaporean e-commerce markets.

\subsection{Research Question and Hypotheses}

The main research question formulated out of this study will be "How will the consumers' buying behaviors affect the e-commerce environment?". Based on the main research question, a sub-research question was then constructed "Which type of factors may cause an impact on the consumers' buying behaviors?"

Hypotheses were created with the research questions being kept in mind. The null hypothesis, $\mathrm{H}_{0}$, will be "consumers' buying behaviors will not affect the e-commerce environment," whereas the alternative hypothesis, $\mathrm{H}_{1}$, will be "consumers' buying behaviors will affect the e-commerce environment."

\section{Literature Overview}

As shown in Figure 1, the research focus will be the intersection between the consumers' buying behaviors and e-commerce, which inter-joins both circles together. Factors regarding what may affect the consumers' buying behaviors and, subsequently, their consequences on the consumer side will be investigated in detail, and the factors that may affect the e-commerce business environment will also be studied.

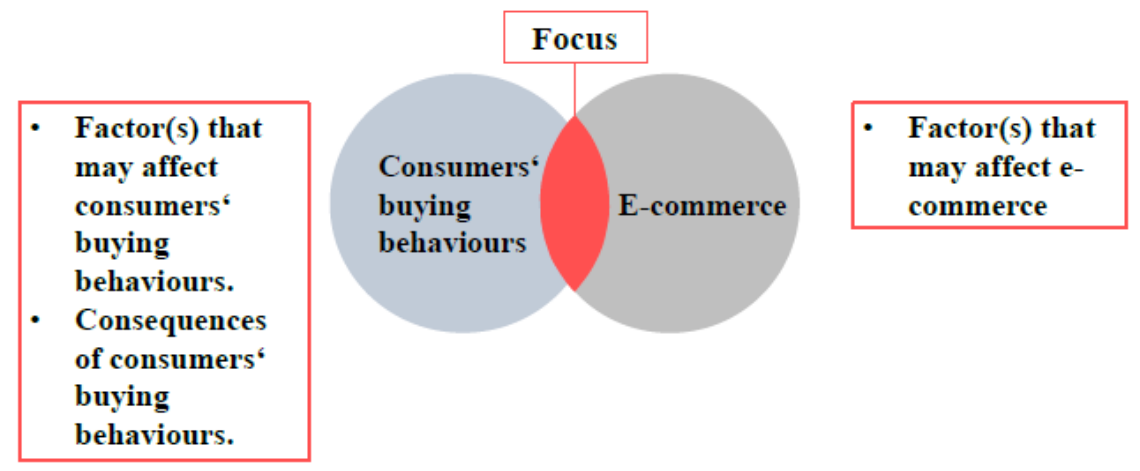

Figure 1. The research's focus

Source: Construction of the authors.

Based on the figure mentioned above, an overview of essential literature regarding the identified focus, which explains the previous work and relevant theories related to this context, will be found in the following paragraphs. The journal papers and articles chosen for this review can be classified into two categories; factors driving consumers' buying behaviors and the rise of e-commerce.

\subsection{Factors Driving Consumers' Buying Behaviours}

Millions of consumers create and reinforce new online buying behaviors and habits (Columbus, 2020). Voinea and Filip (2011) have indicated that in recent years, there has been an emergence and rapid growth of new economic importance, of the new types of consumer - also known as the new consumer - whose attitudes, aspirations, and purchasing patterns are different as compared to those existing behaviors in the past. Among the various reasons behind consumers' buying behaviors, a few significant motivators will be discussed below. Said motivators are concerning competitive prices, customer service, customer reviews, and trust.

\section{Competitive Prices}

Previous research depicts, that prices come into consumers' minds before deciding factors (Guo et al., 2019). For many consumers, competitive pricing stays as the number one reason that attracts their attention and, as a result, positively affects their buying behaviors. The majority of the consumers are usually searching for product offers at very affordable or even discounted prices (Kerick, 2019). As per Urne (2020), competitive pricing remains one of the critical factors for success in e-commerce.

Tanir (2018) states that the most crucial store features driving up to $80 \%$ of consumers' purchasing decisions is competitive pricing. He also mentioned that around $90 \%$ of the e-commerce shoppers are considered the 'masters' of deal hunting. Thanks to the advanced technology and comparison-shopping engines, consumers can now get alerts for multiple items from multiple e-commerce stores that further facilitate their comparison ability 
between the products offered. This comparison will allow the shoppers to get real-time information concerning the lowest best prices for their desired product or service.

\section{Customer Service}

Customer service remains one of the critical touchpoints that affect the buying behavior of consumers. According to Wertz (2017), attracting new customers costs approximately seven times more than retaining the existing customer base. So, the provision of excellent customer service can increase sales and profits and aid the companies, in the long run, to stand out in the virtual competitive marketplace.

\section{Customer Reviews}

Based on an online article from eMarketer, a complete $61 \%$ of respondents said they had checked online reviews, blogs, and other online customer feedback before moving to the next step, purchasing the new product or service. More than $80 \%$ said that such evaluations had held at least some influence on their purchases (eMarketer, n. d.).

This result is further supported by research (Kaushik et al., 2018), which states that the reviews projected on the e-commerce platforms may help certain users during their decision-making process regarding the product itself. A large number of helpful reviews also conveys more information about the product to a customer. Source credibility, review popularity, and usefulness play a vital role in the sales of the product. Their study also confirms the positive effect of the balance of reviews on product sales. Customer reviews can help eliminate any doubts that potential customers may have about their product or may even help when it comes to product selection (Charlton, 2012).

\section{Trust and Loyalty}

Trust is expected to be even more critical in e-commerce than in traditional commerce because of the paucity of rules and customs in the regulation of e-commerce and that because online services and products typically are not immediately verifiable by the consumers (Gefen \& Straub, 2004). The research conducted by Teo and Liu (2005) concludes that consumers' trust in e-commerce vendors and their risk perception can also be regarded as behavioral beliefs that may affect consumers' behavioral attitude - to purchase or not to purchase.

Frequently, the lack of trust is a fundamental reason many users will not purchase goods or services from e-commerce websites. Trust is considered the critical factor for maintaining sustained relationships between the transacting consumer and the e-commerce seller (UK Essays, 2018). Coming hand-in-hand with trust comes the loyalty of the consumers. Without the glue of loyalty, even the best-designed e-business model will collapse. Besides purchasing more from the business, loyal customers would frequently refer new friends and family members to the e-business, providing yet another rich source of profits. Referrals are considered lucrative in traditional commerce, but the Internet further amplifies this effect since the word 'mouse and keyboard' spreads even faster with just some clicks than word of mouth (Reichheld \& Schefter, 2000).

\subsection{Rise of E-Commerce}

\subsubsection{Technology}

The new generation can no longer remember a world without computers, emails, and cell phones (Taken, 2009). Raja and Nagasubramani (2018) have reiterated the importance of technology, stating that today's era of the 21st century is often regarded by many as an era of technology. Technology today plays a significant role in our life. It is frequently associated with growth, as it is seen as a basis of the growth of an economy. Information technology and the Internet have dramatically affected business operations and continue to affect business conduct dramatically. The ongoing technological wave transforms markets, industries, and businesses (Dinu \& Dinu, 2014). Business as a whole is changing, thanks to technology and its advancements (Pierson, 2018).

\subsubsection{A Need for Tech Savviness}

As more technological advances enter the picture and an entirely digital world is foreseen to emerge shortly, many people are "pushed" or even "forced" to educate themselves on the new technology to not be left behind and remain up to date with society. The more technologically literate one is, the better-prepared one will be able to adapt to any form of change (Pierson, 2018). Nowadays, upskilling in technology is becoming a necessity rather than a choice (Rao, 2020).

With our ever-changing environment and the shift from traditional to virtual settings, people need to be equipped with technical skills. Technology will empower the human race and will open up opportunities that were otherwise impossible to reach before. Gupta (2006) illustrates the need to be computer literate. Employers nowadays prefer their workers who are computer literate to those who are not. Computer literacy contributes further to employee and productivity efficiency, therefore making them more valuable to the company. 


\subsubsection{Explosive Growth of E-Commerce}

In our current digital age, e-commerce plays a vital role in our lives. With the unfortunate ongoing global COVID-19 pandemic that restricts people from heading out, many families will eventually replace their store and mall visits permanently with online grocery, apparel, and entertainment shopping (Columbus, 2020). This development further contributes to the extensive growth of the e-commerce environment.

Based on Kerick, the expected growth of e-commerce is to come from Asia and the US to Europe and throughout Africa to the Middle East. The e-commerce sector is expected to break the net, accounting for double-digit growth in all locations worldwide (Kerick, 2019). Taken Smith (2009) states that the annual growth rate of e-commerce is estimated to be up to $28 \%$ at the global level, while individual countries may even have much higher growth rates.

\section{Methodology}

A primary research process that is suitable for this thesis is presented by Karlsson (Karlsson, 2016). Based on this process, the actual methodology to achieve an efficient study has been derived and is illustrated in Figure 2. The first step starts with literature research. This step is followed by the data collection stage, including preparing the questions suitable for the questionnaire and identifying potential participants. The third step deals with the data analysis based on a quantitative review to identify possible correlations and derivations of factors. The evaluation and consolidation of the gathered results will represent the final step of this report.

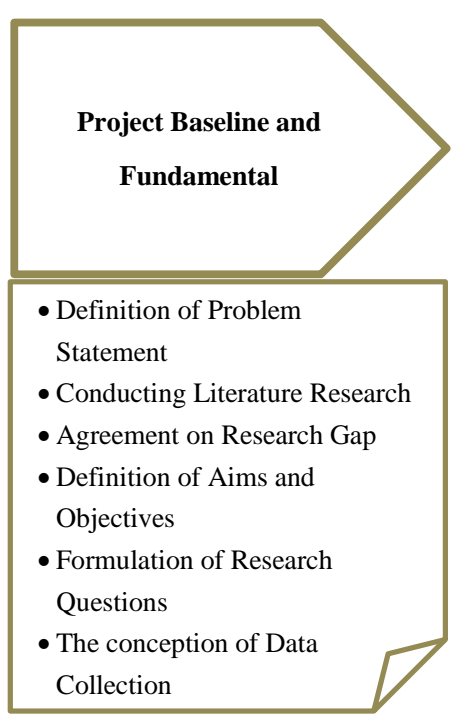

Source: Construction of the authors.



Figure 2. Methodology



- Conducting Quantitative

view of Data

Identification of Possible

Deviation of Factors

\subsection{Research Gap}

After conducting the first round of initial literature research, the studies have revealed that the majority of the literature reviews and focus were concentrated on the topic of e-commerce and was covered mainly on the contents as seen below in table 1 (Loo \& Sze, 2002; Lee et al., 2012; Singh \& Sinha, 2013; Nisa \& Prabhakar, 2017; Wagner et al., 2018; Dai et al., 2018).

Table 1. Adaptation of existing research studies

\begin{tabular}{l}
\hline The existing research was conducted on: \\
\hline E-commerce in general \\
Consumers' buying behaviors in e-commerce \\
Risk assessments in e-commerce \\
Factors determining consumers' e-satisfaction \\
Consumer Trust in e-commerce
\end{tabular}

Source: Construction of the authors. 
A lack of research is observed on the linkage between the consumers' buying behaviors and their impact on e-commerce. Hence, this research will further enrich and contribute to the available data and information by studying the factors affecting consumers' buying behaviors in Singapore and their effect on the e-commerce business environment.

\subsection{Research Design}

For the empirical part of this research, a questionnaire was structured and designed on QuestionPro, distributed to willing participants. However, to ensure that this research would get sufficient datasets, at least 40 participants will be targeted, or the aim will be to gather as many participants as possible within this limited timeframe as there are drop-outs or invalid datasets expected. In surveys, it is always better to have a more significant number of participants as this may also reduce the accidental risk of having an extreme or biased group (Hydrocephalus Association, n.d).

When the questionnaire was completed, the randomly selected participants from personal contacts in Singapore were sent an online link through various communication platforms - primarily through personal contacts and social media to reach a bigger audience. The collation of results would come before the data analysis, as shown in Figure 3. The data will be analyzed in due course with the SPSS statistical software, version 26.



Figure 3. The research design (Construction of the authors)

\subsection{Pretesting of Questionnaire}

Based on the works of Converse and Presser (1986), pre-testing of a survey is a crucial way to pinpoint problem areas, reduce respondent burden, determine whether or not the respondents are interpreting the questions correctly, and ensure that the order of questions does not influence the way the respondent might answer. They have also stated that pre-testing, in other words, is a critical examination of the survey instrument that will help determine if the survey will function adequately as a valid and reliable social science research tool.

Once the setup of the draft questionnaire was completed, a round of pre-testing was conducted. This draft questionnaire was sent out to three participants from Singapore. Pre-testing displayed the possible pitfalls of the questionnaire and if the questions make sense to the participants, and if they would understand what we wish to convey to them.

\subsection{Questionnaire}

The questionnaire was designed and constructed on QuestionPro. The age group ranges from 23 and under, 24 to 39,40 to 55 , to 56 and above. It was structured this way with references made to the generation chart, which would enable the ability to make a comparison and observe if there are any differences to the buying behaviors based on their grouping - for example, take the buying behaviors between Generation X (1965-1980) to the Generation Z (1997 to 2012).

The other questions' construction and structure were created to fit the entire research's objective and aims, firstly with the buying behavior of the participant, and moving onwards to options that either fit the brick and mortar preference of shopping or purchasing online through e-commerce.

Next, the question was set such that when the participant chooses online in Question 5, he/she will be probed with the question "do you prefer to purchase online, rather than in-stores because of:-," of which kind of the factor(s) might affect the participant the most before making their purchases online. Vice versa, if the participant chooses that they prefer to purchase in-store, they will be directed to their last question, "which kind of the factor(s) might affect the participant the most before making their purchases in-stores," and then their questionnaire would end with it. Lastly, the participants who chose to purchase online will be engaged to list the type of the mentioned factors that are the most important to them, which would affect their decisions the most when it comes to purchasing online. 


\section{Results}

A total of 51 responses was collected from Singaporeans with ages ranging between 23 and below to over 55 . However, five participants have dropped out before completing the questionnaire, and the drop-out rate sums up to $9.8 \%$. All in all, there was a collection of 46 useable datasets. Out of the 46 participants, 28 were females, and 18 were males. The majority of the participants (30) were 24 to 39 years old, followed by 11 participants under 23 and 5 participants 40 to 55 years old. The average time that each participant took to complete the questionnaire was approximately 3 to 5 minutes. In the following paragraphs, some interesting findings that were discovered from this research will be discussed.

\subsection{Exciting Findings}

This research has revealed exciting findings of Singaporeans' buying behaviors. Table 2 shows the details of the buying preferences of the participants. Two choices of either purchasing online or in-stores were given. The majority under 23 prefer to purchase in-store, whereas participants between 24 to 40 and above have indicated their online preferences.

Table 2. Participants' buying preferences

\begin{tabular}{lccc}
\hline & $\mathbf{2 3}$ and under & $\mathbf{2 4}$ to 39 & 40 and above \\
\hline Preference to purchase online & 3 & 18 & 5 \\
Preference to purchase in-store & 8 & 12 & 0 \\
\hline
\end{tabular}

Source: Construction of the authors.

Next, the reasons that support their buying preferences, be it online or in-stores, were examined. The reasons given were unavailable stocks for either online or in-store, competitive pricing, loyalty and/or trust issues with online stores or in-stores, and any other reasons that were not listed, where participants can input their reasons specifically. Participants were able to choose more than one option when they deemed fit. Table 3 shows the reasons given by each age group with their preference to either purchase online or in-stores. As seen in table 3 for the online buying preferences, the age group of 23 and under placed an equal weightage on the unavailable stocks in stores due to competitive pricing, loyalty, and trust. The age group between 24 and 30 has indicated competitive pricing as the main reason, followed closely behind by loyalty and/or trust, other reasons, and lastly, unavailable stocks. The other reason raised includes delivery service. The last age group from 40 and above also indicates equal weightage on all the factors mentioned above, and other reasons include convenience, being able to shop from home, and not having to step out of their doorstep.

Table 3. Reasons behind participants' online buying preferences

\begin{tabular}{lccc}
\hline Online & $\mathbf{2 3}$ and under & $\mathbf{2 4}$ to $\mathbf{3 9}$ & $\mathbf{4 0}$ and above \\
\hline Stocks are not in-stores & 1 & 4 & 2 \\
Competitive pricing & 1 & 16 & 2 \\
Loyalty and/or trust & 1 & 5 & 2 \\
Others & - & 5 & 2 \\
\hline
\end{tabular}

Source: Construction of the authors.

In this paragraph, the reasons behind the participants' in-stores buying preferences will be studied. Participants aged 23 and under have chosen loyalty and/or trust and others as their primary motivations behind in-stores purchasing. Other reasons were trying, feeling, or touching the products before purchase, checking the quality, and liking the feel of choosing. For participants between 24 and 39, their preferences are loyalty and/or trust issues and other reasons. The other reasons include similar reasons given before, having the ability to see or try on the products, inspect and test the product or its quality, and see the product they will purchase in person. As none of the participants in the age group of 40 and above chose in-store purchases as their preferences, no data was collected. 
Table 4. Reasons behind participants' in-store buying preferences

\begin{tabular}{lccc}
\hline In-stores & $\mathbf{2 3}$ and under & $\mathbf{2 4}$ to $\mathbf{3 9}$ & $\mathbf{4 0}$ and above \\
\hline Stocks are not online. & - & 1 & - \\
Competitive pricing & - & - & - \\
Loyalty and/or trust & 6 & 6 & - \\
Others & 6 & 7 & - \\
\hline
\end{tabular}

Source: Construction of the authors.

Participants who chose their purchasing preference online were prompted to rate the importance of the four main factors that drive their liking: pricing, customer service, customer reviews, and trust. Participants can rate from a range of 1 to 10 regarding where they place the importance of said factors before they move to the final step - to seal the deal and purchase something from e-commerce. Participants of 23 and under have ranked customer reviews to be of the most importance, followed closely by pricing. Similarly, participants between 24 to 39 showed the same results, with customer reviews ranked as the most important and trailing behind is pricing, which was ranked as their second top impactor. Lastly, 40 and above participants have ranked pricing and trust as the most important and, subsequently, customer reviews.

Table 5. Importance of factors behind participants' online buying preferences

\begin{tabular}{lccc}
\hline Online & 23 and under & 24 to 39 & 40 and above \\
\hline Pricing & 25 & 148 & 38 \\
Customer Service & 22 & 118 & 31 \\
Customer Reviews & 26 & 149 & 35 \\
Trust & 18 & 130 & 38 \\
\hline
\end{tabular}

Source: Construction of the authors.

\subsection{T-Test Analysis}

T-test analysis was chosen to analyze the factors that may or may not affect the consumers' buying behaviors. A convenient significance value of $0.05 \%$ was assumed throughout this entire research.

\subsubsection{Pricing Factor}

In this paragraph, the T-test results on the four factors, namely pricing, customer service, customer reviews, and trust, will be analyzed briefly. Figure 4 shows the T-test analysis conducted on the pricing factor. The null hypothesis can be rejected with a p-value of 0.039 , which is lesser than $0.05 \%$. Based on this result, the pricing factor may potentially affect a consumer's buying behavior in e-commerce.

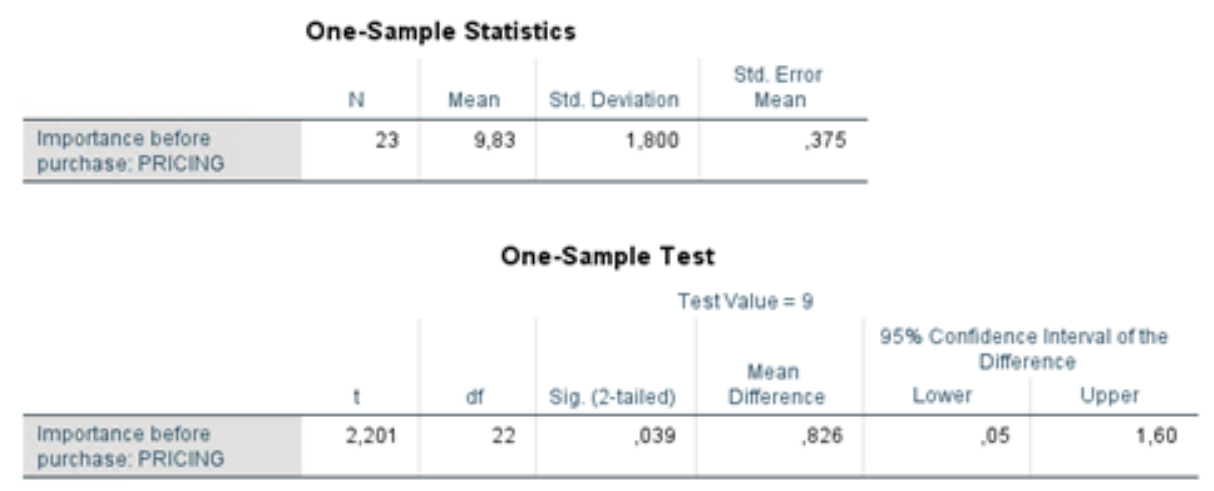

Figure 4. T-test analysis of pricing factor

\subsubsection{Customer Service Factor}

Next, the customer service analysis will be shown. Figure 5 shows the results of the T-test analysis on the customer service factor. With a p-value of 0.266 , which exceeds $0.05 \%$, the null hypothesis cannot be rejected. $\mathrm{So}$, in this case, the customer service factor may potentially not affect a consumer's buying behavior in e-commerce. 


\begin{tabular}{|c|c|c|c|c|}
\hline \multicolumn{5}{|c|}{ One-Sample Statistics } \\
\hline & N & Mean & Std. Deviation & $\begin{array}{l}\text { Std. Error } \\
\text { Mean }\end{array}$ \\
\hline SERVICE & 23 & 7,65 & 2,740 &, 571 \\
\hline
\end{tabular}

\begin{tabular}{|c|c|c|c|c|c|c|}
\hline \multicolumn{7}{|c|}{ One-Sample Test } \\
\hline & \multicolumn{6}{|c|}{ Test Value $=7$} \\
\hline & \multirow[b]{2}{*}{$t$} & \multirow[b]{2}{*}{ df } & \multirow[b]{2}{*}{ Sig. (2-tailed) } & \multirow{2}{*}{$\begin{array}{c}\text { Mean } \\
\text { Difference }\end{array}$} & \multicolumn{2}{|c|}{$\begin{array}{c}95 \% \text { Confidence Interval of the } \\
\text { Difference }\end{array}$} \\
\hline & & & & & Lower & Upper \\
\hline SERVICE & 1,141 & 22 & 266 & 652 &,- 53 & 1,84 \\
\hline
\end{tabular}

Figure 5. T-test analysis of customer service factor

\subsubsection{Customer Reviews Factor}

Following this, the customer reviews factor will be tested. Figure 6 shows the T-test analysis on the customer reviews factor. The null hypothesis cannot be rejected with a high p-value of 0.852 , exceeding the significance value of $0.05 \%$. With this result, the customer reviews factor may potentially not affect a consumer's buying behavior.

\begin{tabular}{l|c|r|r|r}
\multicolumn{5}{c}{ One-Sample Statistics } \\
& $N$ & Mean & Std. Deviation & \multicolumn{1}{c}{$\begin{array}{c}\text { Std. Error } \\
\text { Mean }\end{array}$} \\
\hline REVIEWS & 24 & 9,08 & 2,165 &, 442 \\
\hline
\end{tabular}

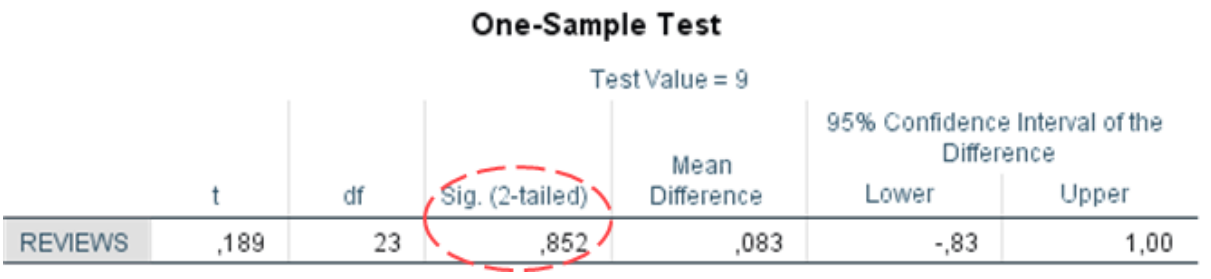

Figure 6. T-test analysis of customer reviews factor

\subsubsection{Loyalty/Trust Factor}

Lastly, the analysis of the loyalty/trust factor will be reviewed. Figure 7 shows the T-test analysis of the loyalty/trust factor. With a p-value of 0.362 , which exceeds the significance value of $0.05 \%$, the null hypothesis could not be rejected. Due to this result obtained, the loyalty/trust factor may also potentially not affect a consumer's buying behavior in the e-commerce environment.

\begin{tabular}{l|r|r|r|r}
\multicolumn{5}{c}{ One-Sample Statistics } \\
& $\mathrm{N}$ & Mean & Std. Deviation & \multicolumn{1}{c}{$\begin{array}{c}\text { Std. Error } \\
\text { Mean }\end{array}$} \\
\hline TRUST & 23 & 8,48 & 2,466 &, 514 \\
\hline
\end{tabular}



Figure 7. T-test analysis of loyalty/trust factor 


\subsection{Correlation Analysis}

Subsequently, after conducting the T-test analyses, a correlation analysis between the four factors was also tested with Pearson's correlation test and the study of each of its significance values. Pearson's $r$ varies between +1 and -1 , where +1 is a perfect positive correlation, and -1 is a perfect negative correlation. With a value of 0 , it means that there is no linear correlation at all (Ezspss, n.d.).

\subsubsection{Pricing Factor}

As seen in Figure 8 and based on Pearson's correlation test, service shows a weak correlation to pricing with an $\mathrm{R}$-value of 0.015 . Customer reviews show a negative correlation of -0.021 with pricing, whereas loyalty/trust shows a weak correlation with a value of 0.132 . However, the significance test indicates otherwise. With a p-value of 0.946 , the results have insufficient evidence to prove that correlation exists between service and pricing. Similarly, the p-value was also higher for the other two factors than the convenience value of $0.05 \%$. Thus, it has shown insufficient evidence to prove correlations between customer reviews and loyalty/trust to the pricing factor.



Figure 8. Correlation analysis with the pricing factor

\subsubsection{Customer Service Factor}

Figure 9 depicts the correlation between the customer service factor with customer reviews and loyalty/trust. Based on Pearson's correlation, customer review holds a weak correlation to customer service with an R-value of 0.251 . Similarly, loyalty/trust also holds a weak correlation to customer service, with a value of 0.261 . However, the significance test proves otherwise. With a p-value of 0.248 and 0.229 for customer reviews and loyalty/trust, both values exceed $0.05 \%$ and thus show insufficient evidence to prove that the correlations exist between customer reviews and loyalty/trust to the customer service factor.

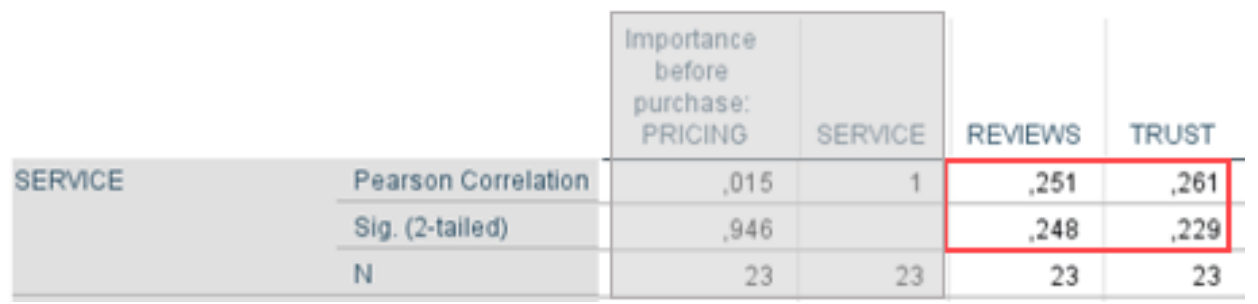

Figure 9. Correlation analysis with the service factor

\subsubsection{Customer Reviews and Loyalty/Trust Factor}

Figure 10 below shows the last correlation test conducted for customer reviews and loyalty/trust. Based on Pearson's correlation, customer review has a weak correlation to loyalty/trust. However, the significance test indicates a different result. With a p-value of 0.195 , there is insufficient evidence to show the correlation between customer reviews and loyalty/trust.

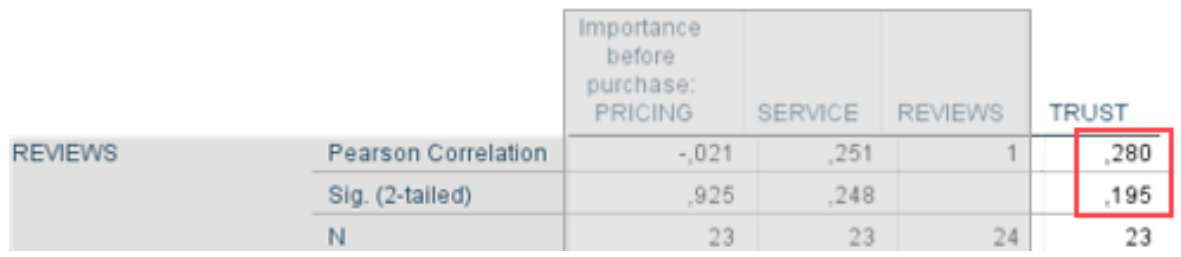

Figure 10. Correlation analysis with the customer reviews and loyalty/trust factor 


\section{Interpretation of Results}

In the upcoming paragraphs, the interpretation of the results can be found and will be discussed.

\subsection{Buying Preferences}

Figure 11 displays the graphical representation of the buying preferences. The graph exhibits an increasing slope of the buying preferences of Singaporeans as the age group rises. The intersection identified between the first two age groups displays the change in the buying preferences, from purchasing in-stores to buying online. This trend supports and highlights the relevance of this research and e-commerce's increasing popularity in Singapore.

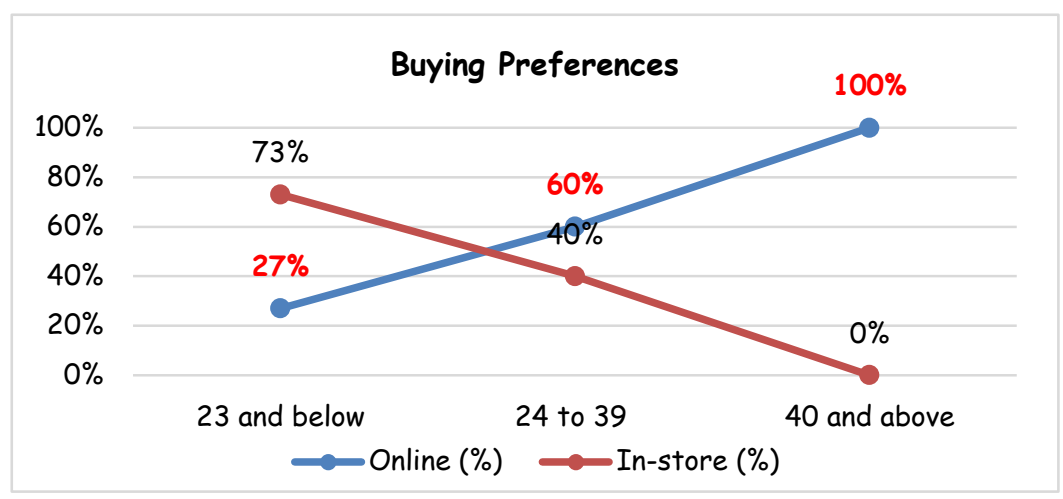

Figure 11. Graphical representation of Singaporeans buying preferences

\subsection{Correlation Analysis}

Based on Pearson's test, some weak signs of correlation between the four factors exist. A positive correlation indicates a relationship between two variables, where if one variable increases, the other one would also increase (Your Dictionary, n.d.). In this research's case, when the pricing increases, the customer service factor may also increase and vice versa for all the other factors with positive correlations. Also, all the correlations were relatively weak, with R-values approximately around 0.1 to 0.2 , indicating only a weak relationship between the factors. The negative correlation between pricing and customer reviews could be that customer reviews may decrease in value when pricing increases. However, after checking these results with the significance test, the outcomes have proven otherwise. There is insufficient evidence to confirm that the correlations exist.

\section{Conclusion}

The following paragraphs will discuss the identified results, limitations, and areas for future work from this research.

Based on the findings, at least one of the factors - in this case, pricing may impact a Singaporean consumer's buying behaviors in e-commerce. The results from the three other factors - customer service, customer reviews, and loyalty/trust- have revealed that it may not impact the consumers' buying behaviors online. There might have been a probable but weak correlation of the factors with one another. However, the significance test has shown insufficient evidence to support Pearson's correlation test results. Other factors besides the four main factors were also raised in this research, and this could be considered possible influences to affect the participants' not to choose to buy in-stores instead.

Lastly, the participants' favorite way to purchase has observed a shift from the age group of 23 and below, where the majority of the participants prefers to purchase in-stores whereas the age group from 24 to 40 and above are more welcomed to the ideas of purchasing online and thus prefers to shop and buy online instead of in-stores.

There are several limitations to this research study. They are made for the general e-commerce context, with no specific targeted e-commerce industries in mind. It was not possible to appeal to a larger audience for the questionnaire responses with a limited timeframe. This research was also limited to the studies of one specific country's (Singapore) buying behaviors in e-commerce. As this research is limited to a study conducted with 46 inputs, it limits the generalization of this work's results and interpretations.

Further research could create and research concerning the targeted e-commerce industry. To generalize the results and interpretations, more participants would be recommended. Further works could include quantifying the interrelation of buying behaviors' factors and their potential impact on e-commerce. Another area would also address the other reasons raised in this research as potential factors that may affect a consumer's buying behavior. 
Lastly, a comparison of purchasing behaviors between an emerging and a developed market could be made and, after that, compare how the results will differ.

\section{References}

Charlton, G. (2012). Ecommerce consumer reviews: Why you need them and how to use them. Retrieved from https://econsultancy.com/ecommerce-consumer-reviews-why-you-need-them-and-how-to-use-them/

Columbus, L. (2020). How COVID-19 Is Transforming E-Commerce. Retrieved from https://www.forbes.com/sites/louiscolumbus/2020/04/28/how-covid-19-is-transforming-e-commerce/\#2774 $6 \mathrm{f} 103544$

Converse, J. M., \& Presser, S. (1986). Survey Questions: Handcrafting the Standardized Questionnaire. United States of America: Sage Publications. https://doi.org/10.4135/9781412986045

Dai, Y. N., Viken, G., Joo, E., \& Bente, G. (2018). Risk assessment in e-commerce: How sellers' photos, reputation scores, and the stake of a transaction influence buyers' purchase behavior and information processing. Computers in Human Behavior, 84, 342-351. https://doi.org/10.1016/j.chb.2018.02.038

Dinu, G., \& Dinu, L. (2014). Using the Internet as a Commercial Tool: A Case Study of E-Commerce in Resita. Procedia Engineering, 469-476. https://doi.org/10.1016/j.proeng.2014.03.014

eMarketer. (2008). Online Reviews Sway Shoppers. Consumers look for peer opinions. Retrieved from https://www.emarketer.com/Article/Online-Reviews-Sway-Shoppers/1006404

Ezspss. (n. d.) Pearson Correlation Coefficient and Interpretation in SPSS. Retrieved from: https://ezspss.com/pearson-correlation-coefficient-and-interpretation-in-spss/

Gefen, D., \& Straub, D. W. (2004). Consumer trust in B2C e-Commerce and the importance of social presence: $\begin{array}{lllll}\text { Experiments in e-Products and } & \text { e-Services. }\end{array}$ https://doi.org/10.1016/j.omega.2004.01.006

Guo, M., Liao, X., Liu, J., \& Zhang, Q. (2019). Consumer preference analysis: A data-driven multiple criteria approach integrating online information. Omega, 96. https://doi.org/10.1016/j.omega.2019.05.010

Gupta, G. K. (2006). Computer Literacy: Essential in Today's Computer-Centric World. ACM SIGCSE Bulletin. https://doi.org/10.1145/1138403.1138446

Hydrocephalus Association. (n. d.). Research 101: The Importance of Sample Size. Retrieved from https://www.hydroassoc.org/research-101-the-importance-of-sample-size/

Karlsson, C. (2016). Research methods for operations management (2nd ed.). Abingdon, and New York: Routledge. https://doi.org/10.4324/9781315671420

Kaushik, K., Mishra, R., Rana, N. P., \& Dwivedi, Y. K. (2018). Exploring reviews and review sequences on e-commerce platform: A study of helpful reviews Amazon. Journal of Retailing and Consumer Services, 45, 21-32. https://doi.org/10.1016/j.jretconser.2018.08.002

Kerick, F. (2019). The Growth of eCommerce. Retrieved from: https://medium.com/swlh/the-growth-of-ecommerce-2220cf2851f3

Lee, J., Lee, Y., \& Lee, Y. J. (2012). Do customization programs of e-commerce companies lead to a better relationship with consumers? Electronic Commerce Research and Applications, 11(3), 262-274. https://doi.org/10.1016/j.elerap.2011.10.004

Loo, L. S., \& Sze, M. K. (2002). Singapore's Internet shoppers and their impact on traditional shopping patterns. Journal of Retailing and Consumer Services, 9(2), 115-124. https://doi.org/10.1016/S0969-6989(01)00029-7

Moore, K. (n. d.) Ecommerce 101 + The History of Online Shopping: What The Past Says About Tomorrow's Retail Challenges. Retrieved from https://www.bigcommerce.com/blog/ecommerce/\#ecommerce-timeline

Nisar, T. M., \& Prabhakar, G. (2017). What factors determine e-satisfaction and consumer spending in e-commerce retailing? Journal of Retailing and Consumer Services, 39, 135-144. https://doi.org/10.1016/j.jretconser.2017.07.010

OECD. (n. d.) Implications of E-commerce for Competition Policy. Retrieved from https://www.oecd.org/daf/competition/e-commerce-implications-for-competition-policy.htm

Pierson, F. (2018). Why Becoming Tech Savvy is Good for You. Retrieved from 
https://it.toolbox.com/blogs/finneganpierson/why-becoming-tech-savvy-is-good-for-you-011018

Raja, P., \& Nagasubramani, P. C. (2018). Impact of modern technology in education. Journal of Applied and Advanced Research, 33-35. https://doi.org/10.21839/jaar.2018.v3iS1.165

Rao, A. (2020). Tech Upskilling - The why and how. Retrieved from https://www.peoplemattersglobal.com/article/hr-technology/tech-upskilling-the-why-and-how-24899

Reichheld, F. F., \& Schefter, P. (2000). E-Loyalty: Your Secret Weapon on the Web. Retrieved from https://hbr.org/2000/07/e-loyalty-your-secret-weapon-on-the-web

Singh, S., \& Sinha, P. (2013). Consumer Buying Behaviour and E-Commerce - An Indian Perspective. Journal of Advanced Management Science, 1(2), 250-254. https://doi.org/10.12720/joams.1.2.250-254

Statista. (2020). Retail e-commerce sales worldwide from 2014 to 2023 (in billion US dollars). Retrieved from https://www.statista.com/statistics/379046/worldwide-retail-e-commerce-sales/

Statista. (n. d.) E-commerce Singapore (in a million US dollars). Retrieved from https://www.statista.com/outlook/243/124/ecommerce/singapore [Last accessed on 15/10/2020]

Taken, S. K. (2009). Worldwide Growth of E-Commerce. Research Gate. https://doi.org/10.1201/9781439809426-c4

Tanir, B. (2018). Pricing Strategy: The Ultimate Guide to E-commerce Pricing. Retrieved from https://prisync.com/blog/ultimate-ecommerce-pricing-strategies/

Teo, S., H, T., \& Liu, J. (2005). Consumer trust in eCommerce in the United States, Singapore and China. Omega, 35, 22-38. https://doi.org/10.1016/j.omega.2005.02.001

The Open University. (n. d.) Social marketing. Retrieved from https://www.open.edu/openlearn/money-business/business-strategy-studies/social-marketing/content-sectio $\mathrm{n}-3.2$

UK Essays. (2018). Trust And Its Importance in E-Commerce Marketing Essay. Retrieved from https://www.ukessays.com/essays/marketing/trust-and-its-importance-in-e-commerce-marketing-essay.php? vref $=1$

Urne, A. C. (2020). Impact of E-Commerce on Consumer Buying Behaviour: A Review of Existing Literature. Research Gate.

Voinea, L., \& Filip, A. (2011). Analyzing the Main Changes in New Consumer Buying Behavior during Economic Crisis. International Journal of Economic Practices and Theories, 1(1), 14-19.

Wagner, G., Schramm-Klein, H., \& Steinmann, S. (2018). Online retailing across e-channels and e-channel touchpoints: Empirical studies of consumer behavior in the multichannel e-commerce environment. Journal of Business Research, 107, 256-270. https://doi.org/10.1016/j.jbusres.2018.10.048

Wertz, J. (2017). Exceptional Customer Service Is Key to E-Commerce Growth. Retrieved from https://www.forbes.com/sites/jiawertz/2017/08/18/exceptional-customer-service-is-key-to-e-commerce-gro wth/\#4f88b7053dc6

Wikipedia. (2020). Generation. Retrieved from https://en.wikipedia.org/wiki/Generation

Wonderflow. (2019). Why is e-commerce winning against retail? Retrieved from https://www.wonderflow.co/blog/why-is-e-commerce-winning-against-retail

Your Dictionary. (n. d.). Positive Correlation Examples in Real Life. Retrieved from https://examples.yourdictionary.com/positive-correlation-examples.html

\section{Copyrights}

Copyright for this article is retained by the author(s), with first publication rights granted to the journal.

This is an open-access article distributed under the terms and conditions of the Creative Commons Attribution license (http://creativecommons.org/licenses/by/4.0/). 